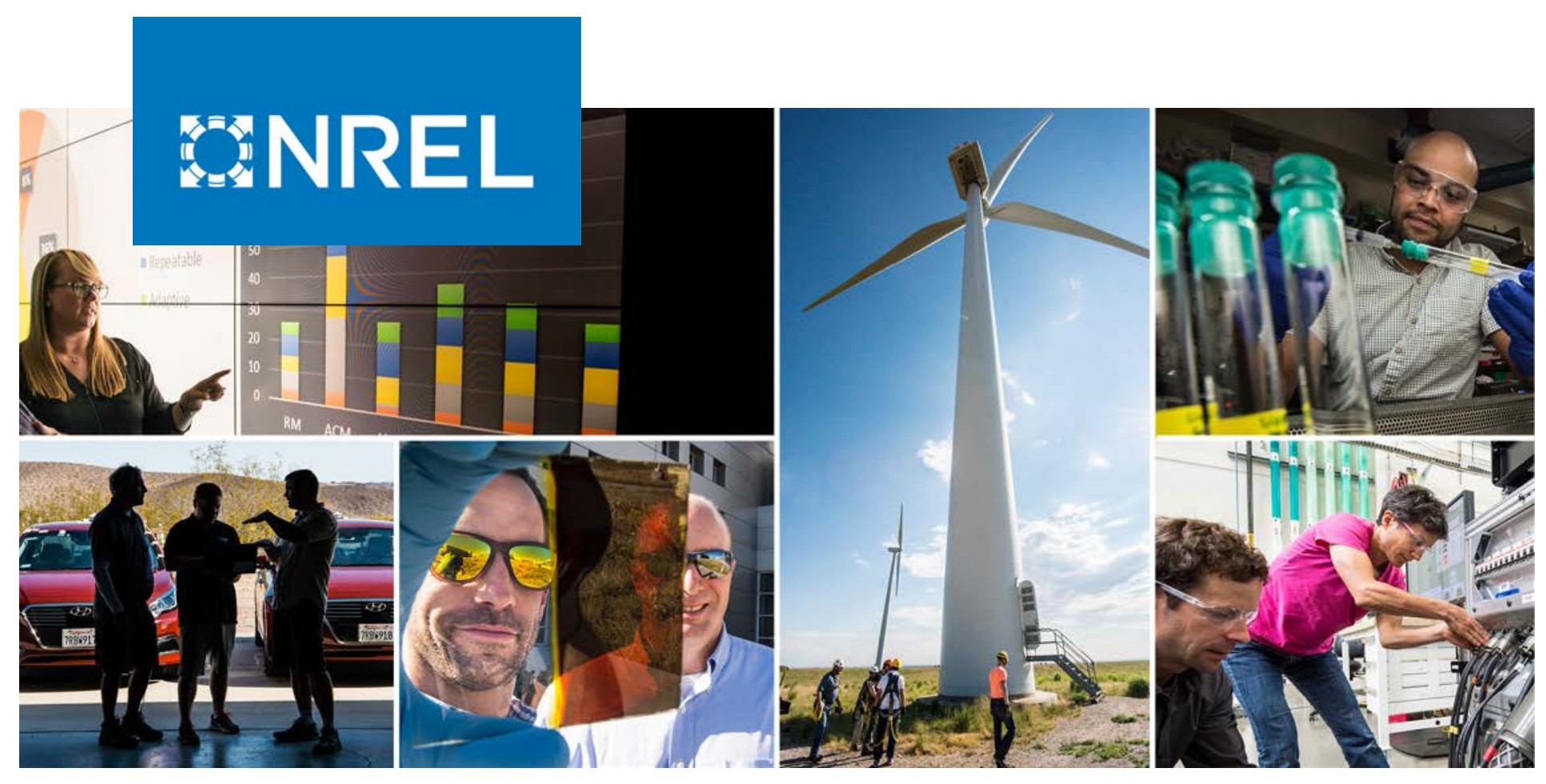

\title{
Automated Transit Fleet Electrification Planning in Response to Route Dynamics, Vehicle Utilization, and Local Climate
}

Karen Ficenec, ${ }^{1}$ Grant Payne, ${ }^{1}$ Eric Miller, ${ }^{1}$ Matthew Moniot, ${ }^{1}$ Narayanan Sankar, ${ }^{2}$ Namit Singh, ${ }^{2}$ and Jonathan Levy ${ }^{2}$

1 National Renewable Energy Laboratory

2 Microgrid Labs

NREL is a national laboratory of the U.S. Department of Energy Office of Energy Efficiency \& Renewable Energy

Operated by the Alliance for Sustainable Energy, LLC

This report is available at no cost from the National Renewable Energy Laboratory (NREL) at www.nrel.gov/publications.
Technical Report

NREL/TP-5400-79876

June 2021 


\title{
GNREL
}

\section{Automated Transit Fleet Electrification Planning in Response to Route Dynamics, Vehicle Utilization, and Local Climate}

\author{
Karen Ficenec, ${ }^{1}$ Grant Payne, ${ }^{1}$ Eric Miller, ${ }^{1}$ Matthew Moniot, ${ }^{1}$ \\ Narayanan Sankar, ${ }^{2}$ Namit Singh, ${ }^{2}$ and Jonathan Levy ${ }^{2}$
}

1 National Renewable Energy Laboratory

2 Microgrid Labs

\section{Suggested Citation}

Ficenec, Karen, Grant Payne, Eric Miller, Matthew Moniot, Narayanan Sankar, Namit Singh, and Jonathan Levy. 2021. Automated Transit Fleet Electrification Planning in Response to Route Dynamics, Vehicle Utilization, and Local Climate. Golden, CO: National Renewable Energy Laboratory. NREL/TP-5400-79876. https://www.nrel.gov/docs/fy21osti/79876.pdf.

NREL is a national laboratory of the U.S. Department of Energy Office of Energy Efficiency \& Renewable Energy Operated by the Alliance for Sustainable Energy, LLC

This report is available at no cost from the National Renewable Energy Laboratory (NREL) at www.nrel.gov/publications.

Contract No. DE-AC36-08GO28308
Technical Report

NREL/TP-5400-79876

June 2021

National Renewable Energy Laboratory 15013 Denver West Parkway Golden, CO 80401

303-275-3000 • www.nrel.gov 


\section{NOTICE}

This work was authored in part by the National Renewable Energy Laboratory, operated by Alliance for Sustainable Energy, LLC, for the U.S. Department of Energy (DOE) under Contract No. DE-AC36-08GO28308. Funding provided by Shell as part of the Shell GameChanger program. The views expressed herein do not necessarily represent the views of the DOE or the U.S. Government.

This report is available at no cost from the National Renewable Energy Laboratory (NREL) at www.nrel.gov/publications.

U.S. Department of Energy (DOE) reports produced after 1991 and a growing number of pre-1991 documents are available free via www.OSTI.gov.

Cover Photos by Dennis Schroeder: (clockwise, left to right) NREL 51934, NREL 45897, NREL 42160, NREL 45891, NREL 48097, NREL 46526.

NREL prints on paper that contains recycled content. 


\section{Acknowledgments}

This work - completed in collaboration with Microgrid Labs-was authored by the National Renewable Energy Laboratory, operated by Alliance for Sustainable Energy, LLC, for the U.S. Department of Energy (DOE) under Contract No. DE-AC36-08GO28308. Funding was provided by Shell as part of the Shell GameChanger program. The authors would like to acknowledge the guidance of Adam Duran, Katie Richardson, and Rachelle Ihly, who coordinated deliverables. The authors also acknowledge Haibin $\mathrm{Xu}$ from Shell for facilitating this collaboration, and without whom this project would not have been possible. The views expressed in this article do not necessarily represent the views of the DOE or the U.S. Government. The views expressed in this article do not necessarily represent the views of Shell. 


\section{List of Acronyms}

BEB battery electric bus

EVSE

electric vehicle supply equipment

FASTSim

Future Automotive Systems Technology Simulator

NREL

SOC

National Renewable Energy Laboratory

state of charge

TMY3

Typical Meteorological Year 3 


\section{Table of Contents}

1 Research Introduction and Motivations ............................................................................

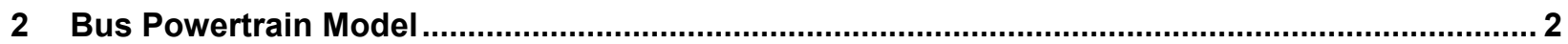

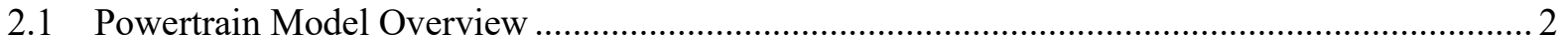

2.2 Ambient Temperature Adjustments ......................................................................... 5

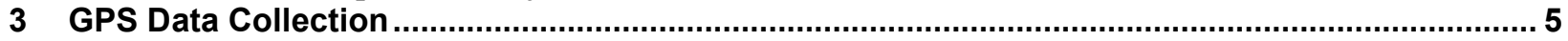

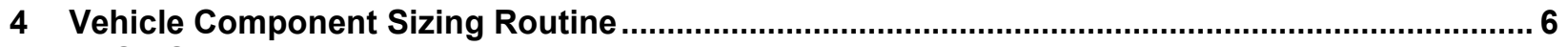

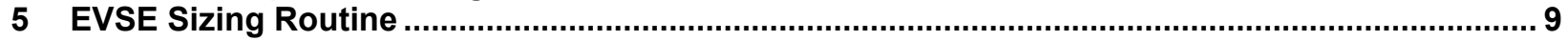

6 Sample Application - Via Mobility ....................................................................................... 11

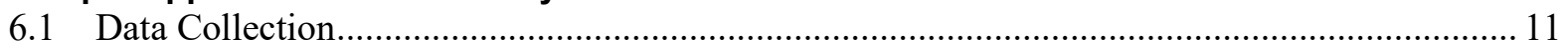

6.2 Sizing Results: Bus Parameters and Required EVSE..................................................... 12

7 Limitations, Conclusions, and Future Work ....................................................................... 14

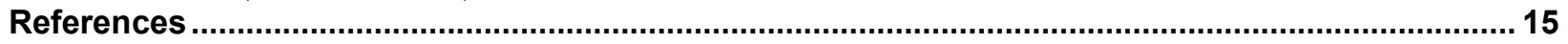




\section{List of Figures}

Figure 1. Motor efficiency map .................................................................................................... 4

Figure 2. BEB powertrain model validation comparing modeled results to measured results ................... 4

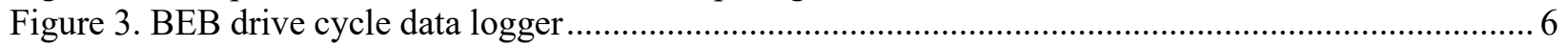

Figure 4. Bus battery and motor sizing workflow......................................................................... 7

Figure 5. Sample penalty surface in response to swept battery and motor sizes ..................................... 9

Figure 6. Energy consumption by vehicle and time...........................................................................

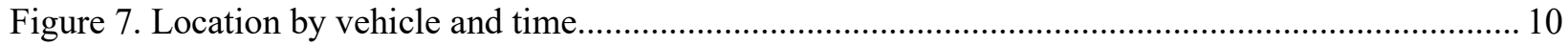

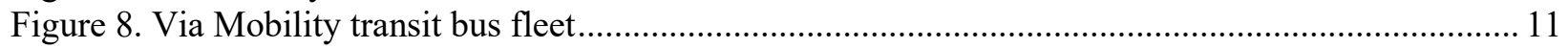

Figure 9. Logger instrumentation and visualization of a sample of data collected................................... 12

Figure 10. Worst observed day of operation for a sample Via transit bus and the worst day of temperatures observed from the nearest TMY3 weather station........................................... 13

Figure 11. Bus battery and motor sizing results for the Via transit bus fleet......................................... 13 


\section{Research Introduction and Motivations}

Transit bus electrification offers many benefits; electric buses are typically cheaper on a life cycle basis [1], exhibit no tailpipe emissions, and reduce greenhouse gas emissions when compared to fossil fuel-powered alternatives [2]. The opportunities associated with electrification of the transit bus fleet has motivated policies worldwide, often with emphasis on the elimination of local air pollution. For example, the Innovative Clean Transit regulation instituted by the California Air Resources Board mandates that $100 \%$ of transit bus purchases by public transit agencies must be zero emissions by 2029, with a 2040 target for all buses within transit fleets [3]. These policies, as well as market factors, have led to the accelerated availability of vehicle options [4] and real-world adoption of electric buses replacing natural gas- and diesel-powered incumbents [5-7].

Despite momentum toward increased electric transit bus proliferation, successful adoption and implementation of battery electric buses (BEBs) into transit fleets is challenging. Whereas transit bus purchases in the past have typically focused on familiar metrics such as bus capacity, purchasing an electric bus requires consideration of a broad range of factors. Most notably, transit agencies must intelligently select the appropriate bus battery size, which is influenced by local climate (both hot and cold), roadway topology, and route dynamics [8]. Depending on the transit agency's route portfolio, an optimal transit fleet may comprise many different buses with different battery sizes. Additionally, transit agencies must also consider the acquisition of electric vehicle supply equipment (EVSE) for battery recharging, with additional determination of the number of plugs, charging power level, and whether en route charging is complementary to route service and justifies the cost. Finally, transit agencies are often poorly funded and segmented across cities with minimal resources to dedicate to understanding how to best electrify their bus fleet.

Combined, the complexity of transit bus acquisition has led to challenges realized during early deployments. BEBs adopted by Albuquerque Rapid Transit in 2018 led to a public lawsuit against the manufacturer, with claims that the buses did not "meet the represented miles-per-charge" [9]. When the Regional Transportation District in Denver began operating BEBs on a short-range downtown route, the agency faced $60 \%$ greater operating costs due to large demand charges associated with bus recharging [10]. An early deployment within the city of Los Angeles resulted in buses being pulled from service due to unreliability and insufficient range [11]. In Boston, transit officials concluded that "the technology is not yet mature enough to support full bus service operation," specifically citing insufficient range during cold temperatures [12]. These challenges are consistent with findings from two National Renewable Energy Laboratory (NREL) deployment evaluations of BEBs within Foothill Transit's bus fleet, finding that although the agency considered the pilot a success, electric bus acquisition must consider route-specific requirements, charging accommodation, and cabin comfort loads $[13,14]$.

The challenges associated with successful BEB adoption and integration into transit fleets motivated a partnership between NREL and Microgrid Labs, leveraging NREL's past experience performing transit electrification feasibility studies [15-17]. The partnership, facilitated by the Shell GameChanger program [18], enabled automation of many agency-specific considerations that previously required time-intensive analysis. One outcome from this project was an automated powertrain sizing workflow. Additionally, the modeling workflow included consideration of required EVSE resources (e.g., plugs, power levels) necessary to support fleet electrification at the 
depot. This report summarizes the theory behind the sizing workflow, based upon physics-based powertrain modeling, to inform intelligent BEB acquisition in accordance with observed transit fleet needs. The following sections introduce the developed powertrain model, solutions for data collection, the powertrain component sizing module, and the depot EVSE sizing module. The report concludes with an example application of the modeling workflow through findings from a real-world pilot with the Via Mobility transit fleet.

\section{Bus Powertrain Model}

\subsection{Powertrain Model Overview}

In order to characterize the energy requirements specific to an individual bus use case, NREL developed a bus variation of the Future Automotive Systems Technology Simulator (FASTSim) modeling tool [19] with a bus motor map and transmission to analyze the necessary power requirements and battery sizes. FASTSim and the derivation used for the modeling workflow solves for the necessary power requirements needed to achieve a given input drive cycle. Inputs to the model are vehicle speed, road grade, and the data sampling increment (timestep). Each component takes a backwards step in series, with the model using calculating power requirements for each component from the chassis to the battery. Equation 1 shows the chronology of the simulation:

$$
\text { Battery } \leftarrow \text { Motor } \leftarrow \text { Transmission } \leftarrow \text { Differential } \leftarrow \text { Wheel } \leftarrow \text { Chassis } \leftarrow \text { Drive Cycle }
$$

In Equation 2, recorded data are used to calculate the total force necessary from the vehicle to meet the driving profile by meeting terms associated with aerodynamic drag, roadway friction, and gradeability:

$$
F_{\text {road }}=m a+C_{d} \rho A_{f} v^{2}+m g C_{r r} \cos (\theta)+m g \sin (\theta)
$$

Where:

$$
\begin{aligned}
& F_{\text {road }}=\text { force necessary to meet driving profile } \\
& a=\quad \text { acceleration from driving profile } \\
& m=\quad \text { vehicle mass } \\
& C_{d}=\text { coefficient of drag } \\
& \rho=\quad \text { air density } \\
& A_{f}=\quad \text { vehicle frontal area } \\
& v=\quad \text { velocity from driving profile } \\
& g=\quad \text { gravitational acceleration } \\
& C_{r r}=\text { coefficient of rolling resistance } \\
& \theta=\quad \text { roadway grade. }
\end{aligned}
$$

The wheel model converts linear force and speed into torque and rotational speed using the radius of the tire in Equations 3 and 4:

$$
\tau_{\text {wheel }}=F_{\text {road }} r_{\text {tire }}
$$




$$
\omega_{\text {wheel }}=\frac{v}{r_{\text {tire }}}
$$

Where:

$$
\begin{aligned}
& \tau_{\text {wheel }}=\text { wheel torque } \\
& r_{\text {tire }}=\text { tire radius } \\
& \omega_{\text {wheel }}=\text { rotational wheel speed }
\end{aligned}
$$

Components with gears will modify the speed and torque using Equations 5 and 6, respectively, using knowledge of the gear ratio. The component efficiency is used to divide the torque in traction $(-1)$ and multiply the torque in regeneration $(+1)$ :

$$
\begin{gathered}
\omega_{\text {motor }}=\omega_{\text {trans }} r_{\text {gear }} \\
\tau_{\text {motor }}=\frac{\tau_{\text {trans }}}{r_{\text {gear }}} \eta_{\text {trans }}^{ \pm 1}
\end{gathered}
$$

Where:

$$
\begin{aligned}
& \omega_{\text {motor }}=\text { rotational output speed of the motor } \\
& r_{\text {gear }}=\text { transmission gear ratio } \\
& \omega_{\text {trans }}=\text { rotational input speed of transmission } \\
& \tau_{\text {motor }}=\text { torque output of the motor } \\
& \tau_{\text {trans }}=\text { torque input of transmission } \\
& \eta_{\text {trans }}^{ \pm 1}=\text { transmission efficiency, multiplied or divided based on traction/regeneration. }
\end{aligned}
$$

Rotational speed and torque are multiplied and divided by gear ratios and efficiencies, respectively, in the driveline until the motor, and the electrical power requirement is calculated according to Equation 7:

$$
P_{\text {battery }}=\tau_{\text {motor }} \omega_{\text {motor }} \eta_{\text {motor }}\left(\tau_{\text {motor }}, \omega_{\text {motor }}\right)^{ \pm 1}
$$

Where:

$$
\begin{aligned}
& P_{\text {battery }}=\text { battery power output } \\
& \eta_{\text {motor }}=\text { motor efficiency calculated using a motor map for torque and speed. }
\end{aligned}
$$

Motor efficiency is a function of speed and torque. Figure 1 displays the motor map used in the model. This efficiency map was derived from electric transit bus data stored in NREL's Fleet DNA database [20]. 


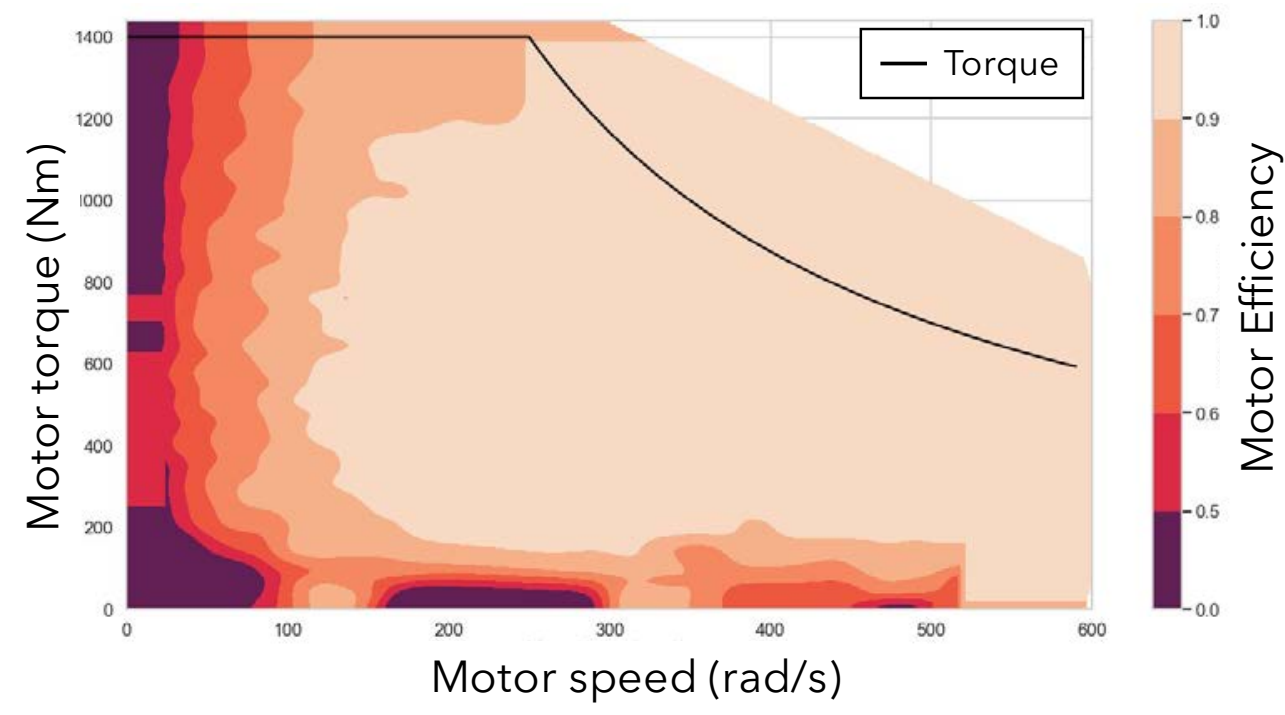

Figure 1. Motor efficiency map

The model was validated using data from BEBs operating in California. The real-world BEB data provided both the speed and GPS traces necessary for FASTSim simulations, as well as the realworld energy consumption serving as the "ground truth" to compare against. In nearly all cases, estimates from FASTSim were more accurate than estimates using per-mile efficiency numbers provided by the manufacturer. This is illustrated for a single trip over time and across many trips in Figure 2. Note that the FASTSim powertrain model is calibrated using physical parameters (e.g., drag coefficient, mass) but excludes thermal effects; these thermal effects contribute to the physics-based model slightly underestimating real-world energy consumption in Figure 2b.

\section{Validation: Single Trip}

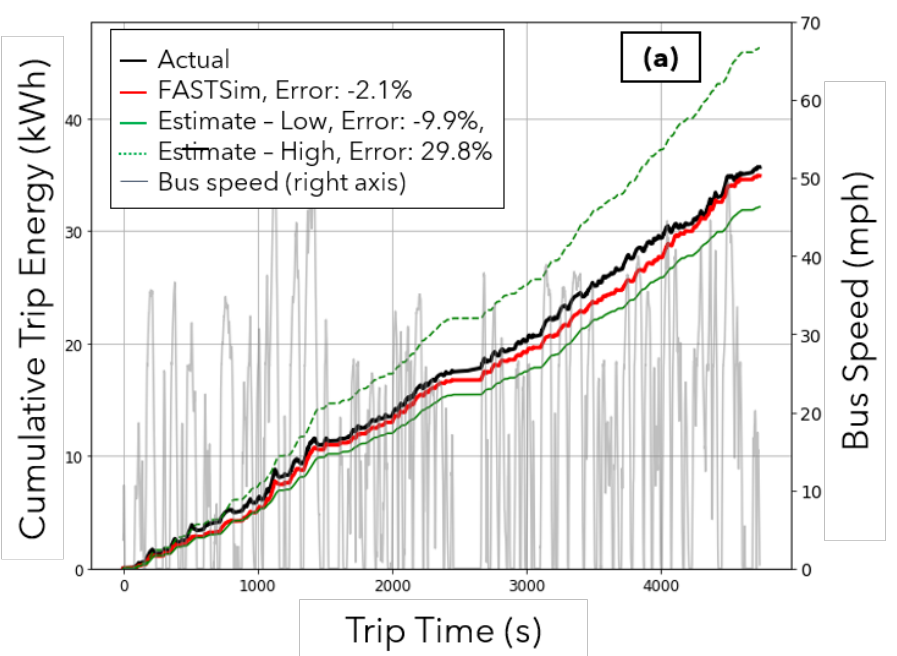

Validation: Multiple Trips

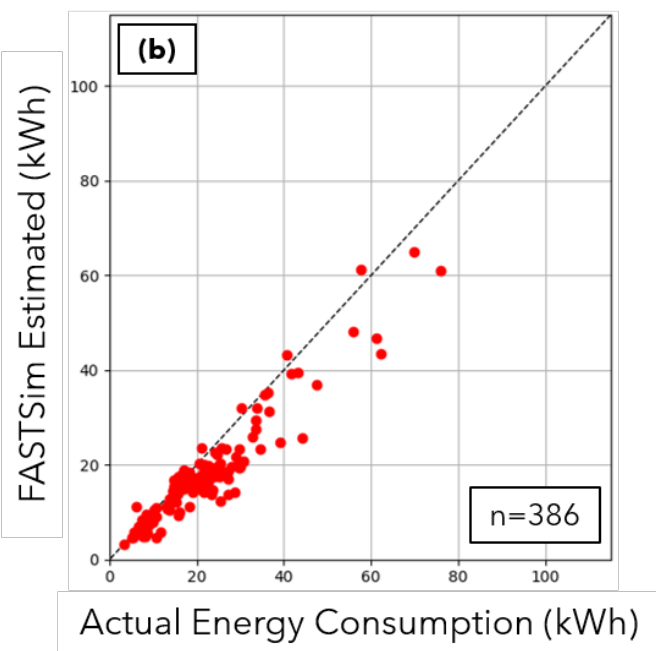

Figure 2. BEB powertrain model validation comparing modeled results to measured results

Finally, the variant of FASTSim used in this modeling framework is also capable of representing recharging during duty cycles from opportunity charging (if available). Opportunity charging 
provides the battery with additional energy at a predefined power level, potentially leading to a smaller required battery size.

\subsection{Ambient Temperature Adjustments}

The physics-based energy calculations in FASTSim do not include auxiliary loads associated with cabin comfort or additional power electronics cooling. Characterization of the energy demands of the cabin were deemed too complex to feasibly incorporate with physical thermal models; bus interiors range in size, and the temperature of the interior is also impacted by frequent door openings and passenger radiant heat. Instead of developing physical thermal models that would be infeasible to accurately implement, empirical relationships between the energy consumption of the bus and ambient temperatures [21] were utilized to adjust the physics-based energy consumption calculated within FASTSim (Equation 8). Penalties were assessed on a relative basis, assuming that FASTSim produces results corresponding to an ambient temperature of $22^{\circ} \mathrm{C}$ with no cabin loads.

$$
P_{\text {battery }}=P_{\text {battery }} \eta_{\text {sys }}\left(T_{a m b}\right)
$$

Where:

$$
\begin{aligned}
& P_{\text {battery }_{a d j}}=\text { the adjusted battery power in response to route demands and temperature } \\
& \eta_{s y s}=\text { empirical energy penalty on the basis of ambient temperature } \\
& T_{a m b}=\text { ambient temperature. }
\end{aligned}
$$

Ambient temperature values specific to a given study location were obtained through use of the Typical Meteorological Year 3 (TMY3) data set [22]. TMY3 data comprise real-world measured values across several years. For each location and month of the TMY3 year, the most representative corresponding month for all years of data at that location is identified. Each of these representative months, from various years, is then aggregated into a single, representative year. In total, there are 8,760 hourly weather values for each of the 1,020 stations for which full yearly weather coverage is available within the United States. To ensure adequate bus operation in the local climate, the nearest weather station to the study location is identified and the worst day of the year on the basis of energy penalty is returned. Hourly weather values for the worst day of the year (and associated energy consumption penalties) are appended to drive cycle data on the basis of time of day during the component sizing routine introduced in Section 4. This approach ensures that buses are sized for the relevant extremes of a location, whether cold or hot.

\section{GPS Data Collection}

Accurate estimation of vehicle energy consumption using FASTSim requires high-fidelity drive cycle data as inputs. Specifically, FASTSim requires second-by-second $(1-\mathrm{Hz})$ vehicle speed and elevation data to obtain accurate results. Although transit agencies typically record high-level data describing operations (e.g., hours per day, miles per day), it is unlikely that a given agency has adequate drive cycle data for FASTSim simulations. Procuring accurate drive cycle data is further hindered by a data-logging market focused primarily on asset tracking with GPS pings based on events rather than recorded at high sample rates. Evaluation of existing data loggers and cost considerations motivated the creation of a custom data logger capable of collecting $1-\mathrm{Hz}$ location, 
speed, and elevation data. Data loggers (example depicted in Figure 3) were constructed using an Adafruit Feather Adalogger [23] in combination with a GPS antenna and DC-DC power converter. The constructed loggers receive power from the bus's Controller Area Network (CAN) bus and are capable of logging data locally for over a year of bus use.

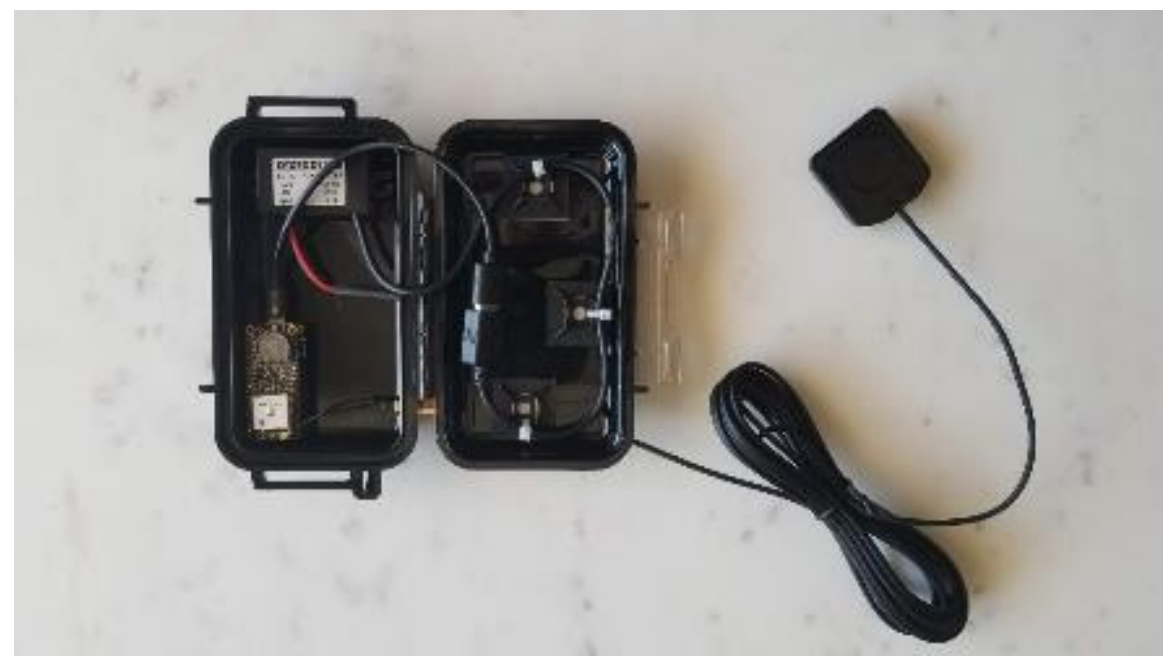

Figure 3. BEB drive cycle data logger

\section{Vehicle Component Sizing Routine}

An ability to procure bus drive cycle data and a validated powertrain model are key ingredients for discovering optimal component sizes needed for successful real-world use. However, an additional wrapper, or sizing workflow, is necessary for orchestrating FASTSim runs to identify the most cost-effective battery and motor sizes. Although cost minimization is a key objective, the sizing workflow is also intended to adequately size buses to meet the needs of the transit agency in question. By sizing buses using real-world route dynamics (e.g., speed, acceleration), roadway topology (obtained through elevation data), and local climate, the approach is considered a significant improvement upon simpler estimates that often assume a fixed vehicle efficiency $(\mathrm{kWh} / \mathrm{mi})$. Additionally, the use of a synthetic grade cycle — starting from rest at a fixed gradeis included to responsibly size the motor in circumstances where buses may be instrumented during periods of minimal observed power demands.

The following steps - also shown in Figure 4 - describe how battery and motor sizes are determined for each bus:

1. A data logger is instrumented on a transit bus over a period of many days (typically a full month). This time period ensures that weekday/weekend effects are observed and a broad understanding of how the bus is used by the agency is obtained.

2. Once collected, drive cycle data are filtered on the basis of days of operation, where days are defined through periods of activity between downtime. Use of midnight for categorization purposes is undesirable as buses operating late-night shifts may cross calendar days. 
3. Each bus-day is input into a static bus model with initial battery and motor sizes to infer the intensity of each day of operational data. The most intensive day is identified on the basis of demanded energy consumption and is retained for parameter sizing.

4. An optimization routine (explained below) is performed, using FASTSim to explore candidate battery and motor sizes over the identified worst day of operation as well as a synthetic grade test. The bus is assumed to be loaded with an intermediate number of passengers during real-world duty-cycle simulations in addition to ambient temperatures from the most extreme day of the year from the nearest TMY3 station. The bus state of charge (SOC) at the beginning of the bus-day is set to $100 \%$, assuming the depot charging routine (described in Section 5) supplies adequate plugs and charging levels. Finally, if opportunity charging is enabled, the bus is provided charging during stops longer than a specified duration during the simulation of the bus-day.

During the grade test, the bus is assumed to be fully loaded with passengers to emulate a worst-case scenario.

5. Battery size and motor size parameters are output for planning consideration. Bus battery and motor sizes are also required as inputs when evaluating the depot EVSE requirements necessary to support an electrified fleet (described in Section 5). Note that the large battery sizes typical of transit buses alleviates the need to size the battery on the basis of peak power. It is assumed that the motor represents the sole power constraint.

\section{$1 \mathrm{~Hz}$ Duty Cycles}
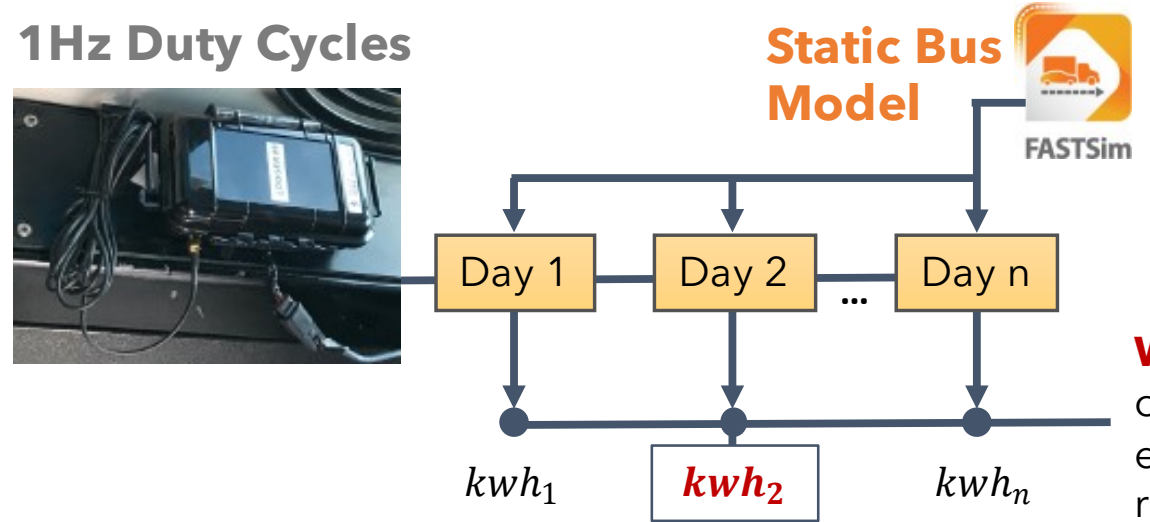

Worst day identified on basis of simulated

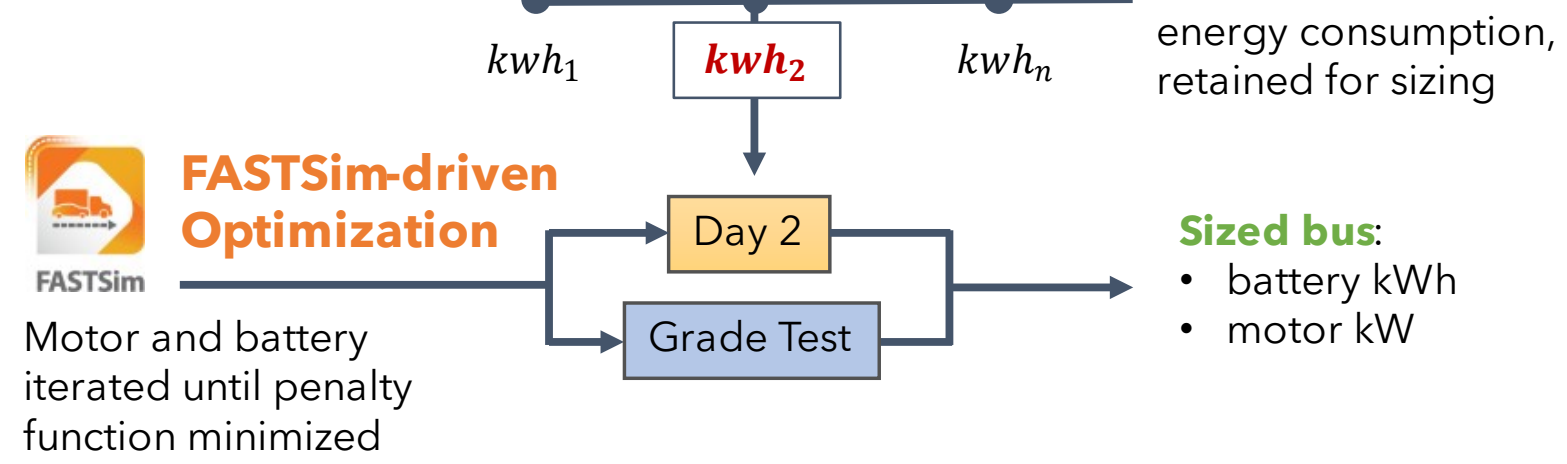

Figure 4. Bus battery and motor sizing workflow

The most critical step in the sizing workflow is the optimization routine, which iterates through different battery and motor size combinations. Discovery of an optimal pair of battery and motor sizes is not trivial; as the battery size increases, so does its mass, requiring a larger motor, which 
may in turn require a larger battery, and so forth. Optimal battery and motor sizes are discovered through minimization of a penalty function (Equation 9) using the Nelder-Mead method [24]. During each iteration, the motor and battery mass values are updated using incremental values ( $\mathrm{kg} / \mathrm{kWh}$ for battery, $\mathrm{kg} / \mathrm{kW}$ for motor) to account for the aforementioned trade-offs.

$$
\text { Penalty }=c_{1} S O C_{\text {Error }}+c_{2} \text { Grade } \text { Error }+c_{3} \text { Delay } y_{\text {Error }}+c_{4} \text { Oversize } \text { Error }
$$

Where:

Penalty $=$ the penalty metric to be minimized

$S O C_{\text {Error }}=\mathrm{SOC}$ error, characterized as remaining miles when battery depletes

Grade $_{\text {Error }}=$ grade error, characterized as the time to accelerate from rest up a hill

Dela $y_{\text {Error }}=$ delay error, characterized as the sum of trace misses throughout the day

Oversize $_{\text {Error }}=$ oversize error, characterized as the total mass of sized components

$c_{1}, c_{2}, c_{3}, \& c_{4}=$ manually calibrated coefficients for balancing penalty types.

The penalty function comprises four terms, each evaluating different performance criteria:

- SOC error evaluates whether or not the bus is capable of completing the worst real-world travel day contained in the data. If the bus is able to make it back to the depot, the error is zero. If the bus cannot return, the error is proportional to the distance remaining in the day. SOC error primarily sizes the bus battery energy.

- Grade error evaluates the ability of the bus to accelerate from stopped on a steep grade, and primarily sizes the bus motor power. The transmission gearing is considered fixed throughout this process.

- Delay error evaluates the ability of the bus to meet trace. Insufficient motor size can result in a bus incapable of matching accelerations and potentially completing routes late. In most cases, delay error is redundant with grade error, although the inclusion of this term is intended to account for buses with aggressive cycles or accelerations at high speeds.

- Oversize error evaluates the total size of the battery and motor and applies a penalty for larger combinations. This term is important to avoid unnecessary oversizing, as significantly large batteries and motors may return promising values for the three other terms but are not cost-effective.

A sample visualization of the penalty function is provided in Figure 5 to illustrate the relationship between component sizes and penalty scores. The penalty score (z-axis) is a function of FASTSim outputs using corresponding battery and motor sizes that define the surface. Inspection of the figure reveals that insufficiently sized motor power and battery energy return extremely high penalty scores. The optimal value is contained within the "feasibility region" of the figure, within which the oversize error is effective at searching for the minimum penalty score. 


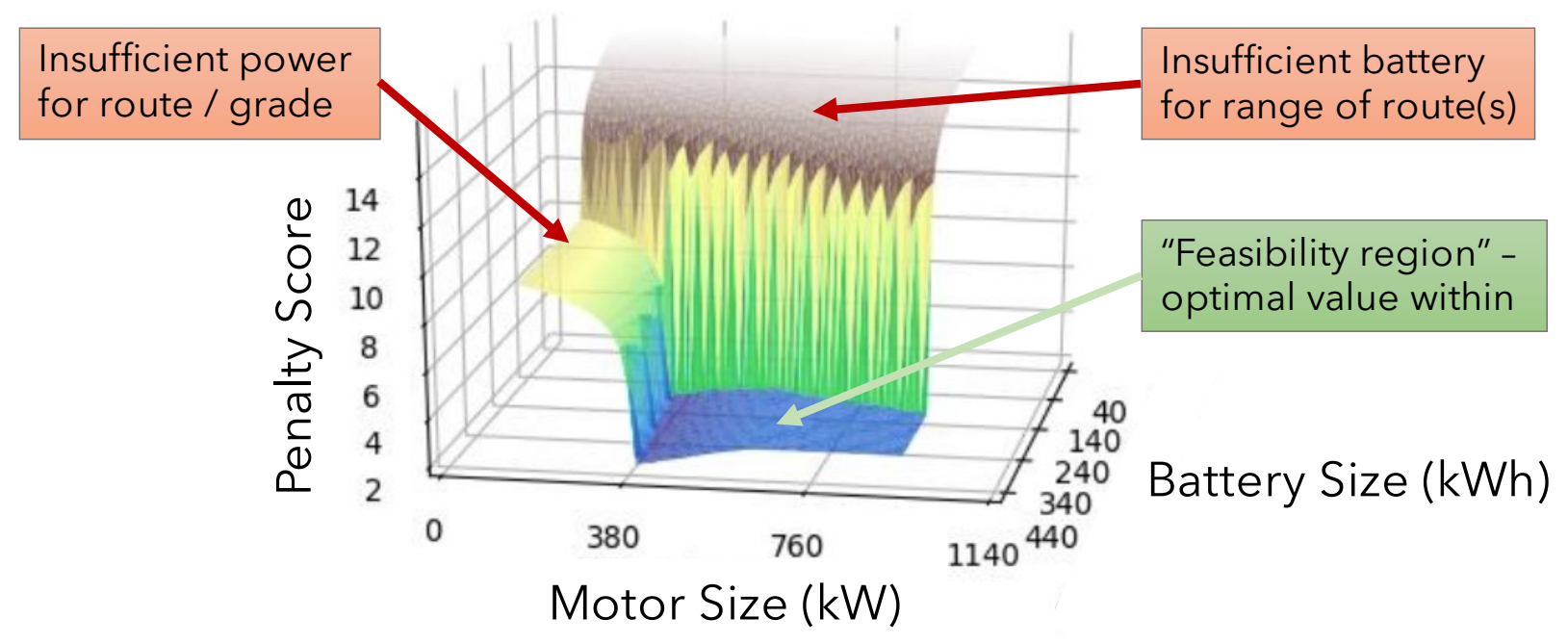

Figure 5. Sample penalty surface in response to swept battery and motor sizes

\section{EVSE Sizing Routine}

EVSE optimization is an exercise in minimizing cost while providing the infrastructure necessary to continue current fleet operations with electric buses. The method works by first compiling simulated electric vehicle energy use into schedules which describe the operation of each vehicle in fixed time intervals (e.g., $15 \mathrm{~min}$ bins). Vehicle stops are categorized geospatially into hexagonal zones to provide a charging opportunity schedule for each vehicle, time bin, and geospatial zone. This analysis must simultaneously consider the charging needs of all vehicles, as depicted through the fleet-wide visualizations in Figure 6 and Figure 7.

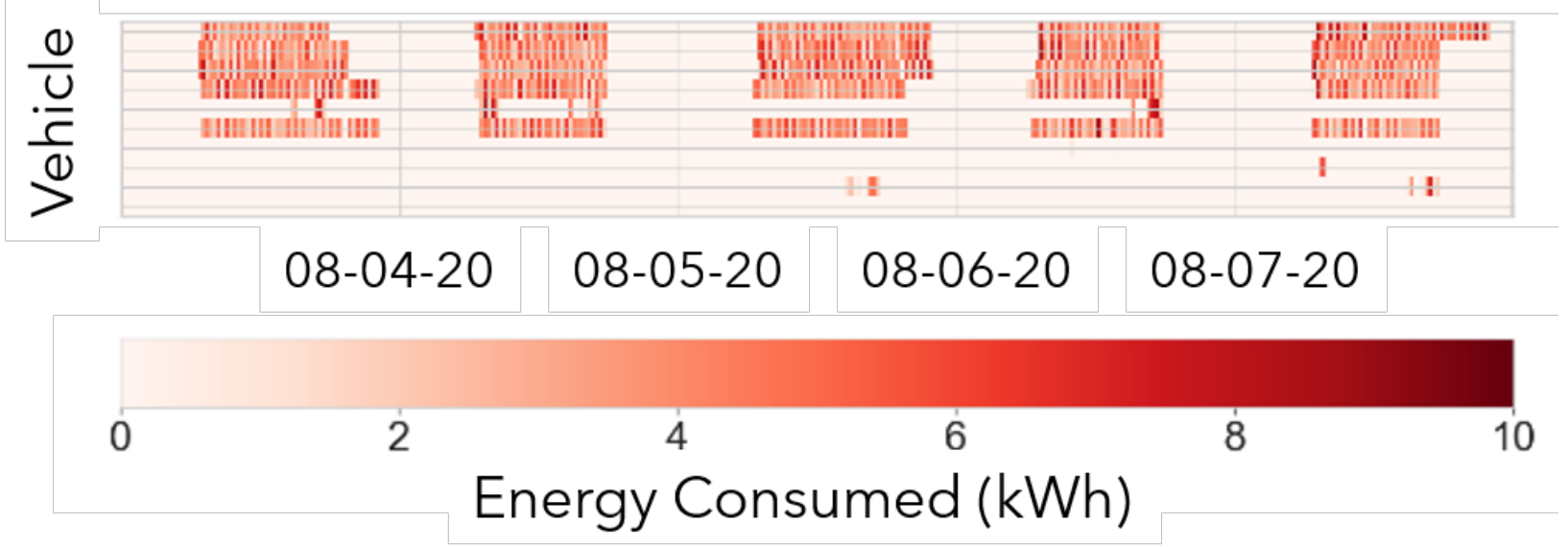

Figure 6. Energy consumption by vehicle and time 


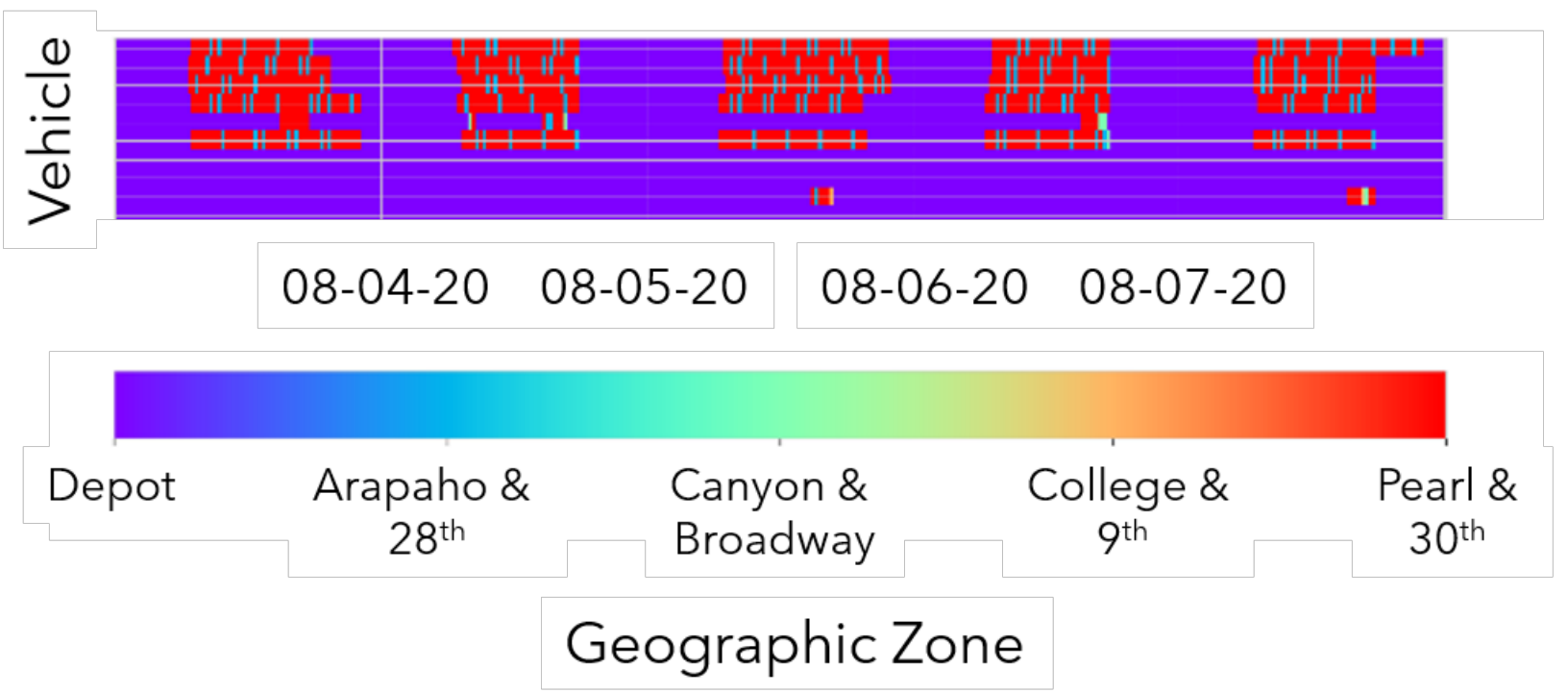

Figure 7. Location by vehicle and time.

Charging Opportunity and energy consumption schedules are used to write a linear programming formulation which minimizes upfront capital costs for electrifying a fleet through judicious choice of infrastructure and battery sizes. The problem statement is:

Minimize:

$$
\sum_{z \in \text { zones }}\left(\psi_{\text {charger }} C_{z}+\psi_{\text {power }} P_{z}\right)+\sum_{v \in \text { vehicles }} \psi_{\text {battery }} B_{v}
$$

Subject to:

The battery cannot discharge below a lower state of charge limit. $B_{v}$ is the battery size for vehicle $\mathrm{v}, D_{v, t}$ is energy discharged by vehicle $\mathrm{v}$ in time bin $\mathrm{t}$, and $E_{v, t}$ is energy charged into vehicle $\mathrm{v}$ in time bin $\mathrm{t}$.

$$
B_{v}+\sum_{t \in 1: T} D+\sum_{z \in \text { zones }} \sum_{t \in 1: T} E_{V, t, z} \geq 0 \forall V \in \text { vehicles, } T \in \text { times }
$$

A battery that begins the day fully charged cannot charge back above $100 \%$ state of charge.

$$
\sum_{t \in 1: T} D_{V, t}+\sum_{t \in 1: T} E_{V, t} \leq 0 \forall V \in \text { vehicles, } T \in \text { times }
$$

A binary variable, $\beta$, registers charging events by vehicle, time, and zone.

$$
P_{\max } \beta_{V, T, Z}-E_{V, T, Z} \geq 0 \forall V \in \text { vehicles, } T \in \text { times, } Z \in \text { zones }
$$


The number of charging events in a time span and zone cannot exceed the number of chargers installed there.

$$
\sum_{v \in \text { vehicles }} \beta_{v, T, Z}-C_{z} \leq 0 \forall T \in \text { times, } Z \in \text { zones }
$$

The energy dispensed by a charger is limited by the power level of chargers installed in that zone.

$$
E_{V, T, Z}-\Delta t_{V, T, Z} P_{Z} \leq 0 \forall T \in \text { times, } V \in \text { vehicles, } Z \in \text { zones }
$$

The result of the optimization routine is a prescribed battery size for each vehicle and number and power level of chargers in each zone, as well as a charging schedule for each bus.

\section{Sample Application - Via Mobility}

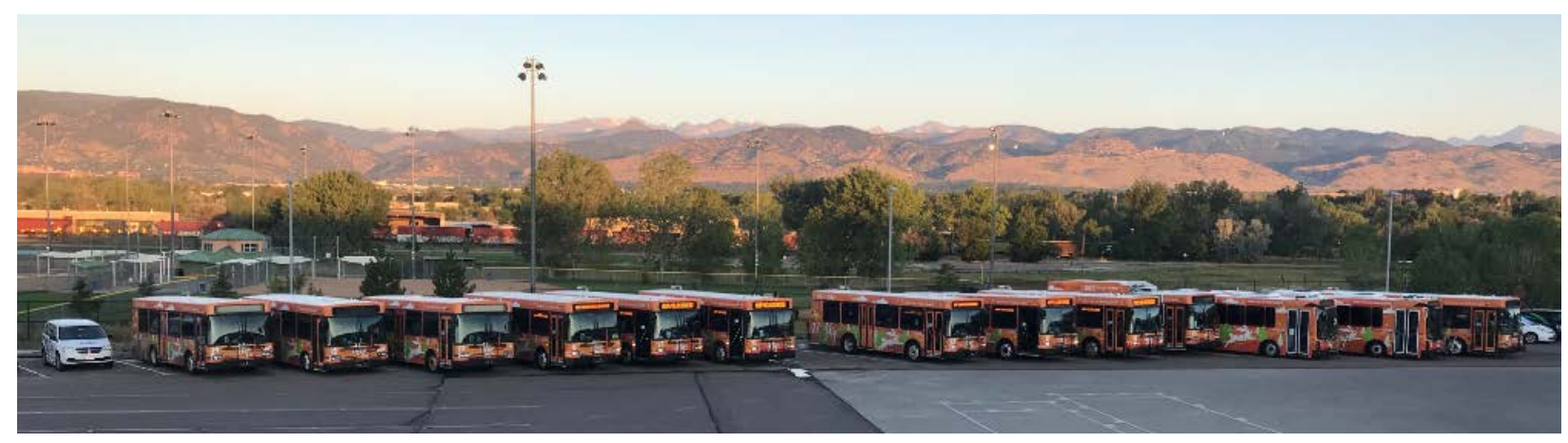

Figure 8. Via Mobility transit bus fleet

This section demonstrates the developed workflow applied to a real-world scenario in collaboration with Via Mobility (hereafter Via). Via is a holistic mobility provider facilitating paratransit, on-demand, charter, and public transit trips based out of Boulder, Colorado. The scope of this pilot was limited to Via's fleet of 15 transit buses (Figure 8), which primarily service the HOP route in downtown Boulder [25].

\subsection{Data Collection}

The dataloggers introduced in the previous section were installed on Via's fleet of transit buses. In total, 12 of the 15 buses were instrumented due to vehicles being down for maintenance during the evaluation period and data being corrupted due to a logger failure (now resolved). At least one month of data was collected for each bus, with a combined 61,598 miles of operational data collected across 829 bus-days of data collection. Analysis of the data revealed that the buses primarily frequented the HOP service route, with occasional charter bus service. Figure 9 illustrates data logger instrumentation and a sample of collected data outlining the HOP route. 

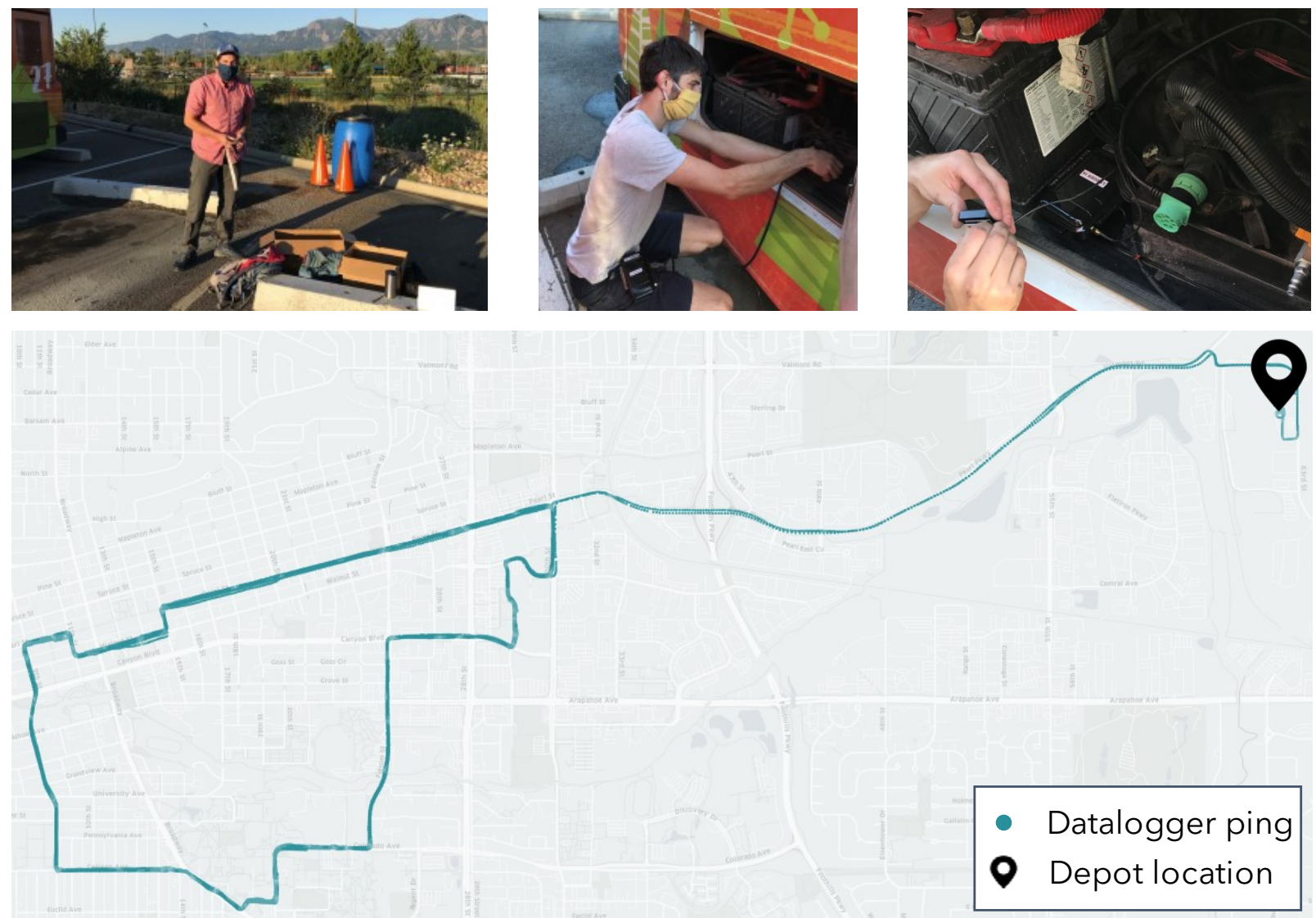

Figure 9. Logger instrumentation and visualization of a sample of data collected

\subsection{Sizing Results: Bus Parameters and Required EVSE}

Data collected from the Via transit fleet were ingested by the sizing module, which iterated over duty cycles for each bus. The sizing module identified the most challenging day of operation for each bus, pairing it with the most extreme day of temperatures associated with a nearby weather station in Boulder, Colorado. The most challenging day of operation is identified using a general bus model and observing the amount of energy required versus other days of route data. Note that this process abstracts the weather occurring during the actual day of operation; the most challenging day of driving in the data is paired with the most severe day of ambient temperatures observed from the nearest weather station. Figure 8 illustrates a sample worst day for Bus 24, during which the bus traveled a total of 113 miles. Temperature values for sizing are also included for reference; the TMY3 data corresponding to the most challenging day of operation throughout the year at the study location were very cold temperatures which demand high heating loads. The bus battery and motor size were determined using this day of operation, in addition to the synthetic grade test introduced in Section 4. 

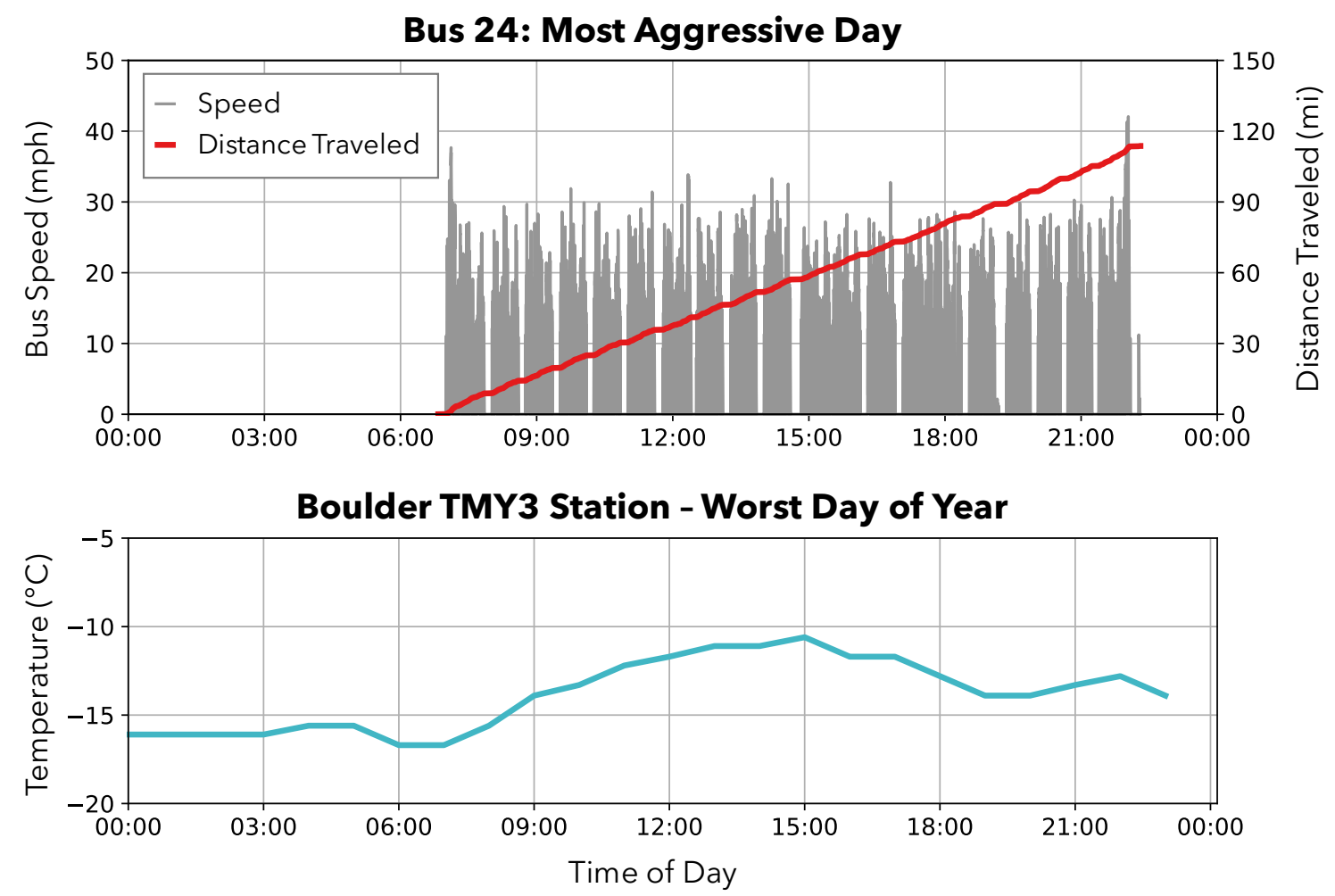

Figure 10. Worst observed day of operation for a sample Via transit bus and the worst day of temperatures observed from the nearest TMY 3 weather station

Sizing results for the remainder of the fleet were obtained in a similar manner and are displayed in Figure 9. The bus sizing results assume no access to opportunity charging in light of the relatively few miles traveled by the fleet vehicles. Overall, the buses are sized similarly, with an average battery size of $243 \mathrm{kWh}$ and an average motor power of $356 \mathrm{~kW}$. The limited variability in powertrain component sizes across buses reflects the logistics underlying the Via transit fleet; each bus is used to service the HOP circulator route in Boulder.
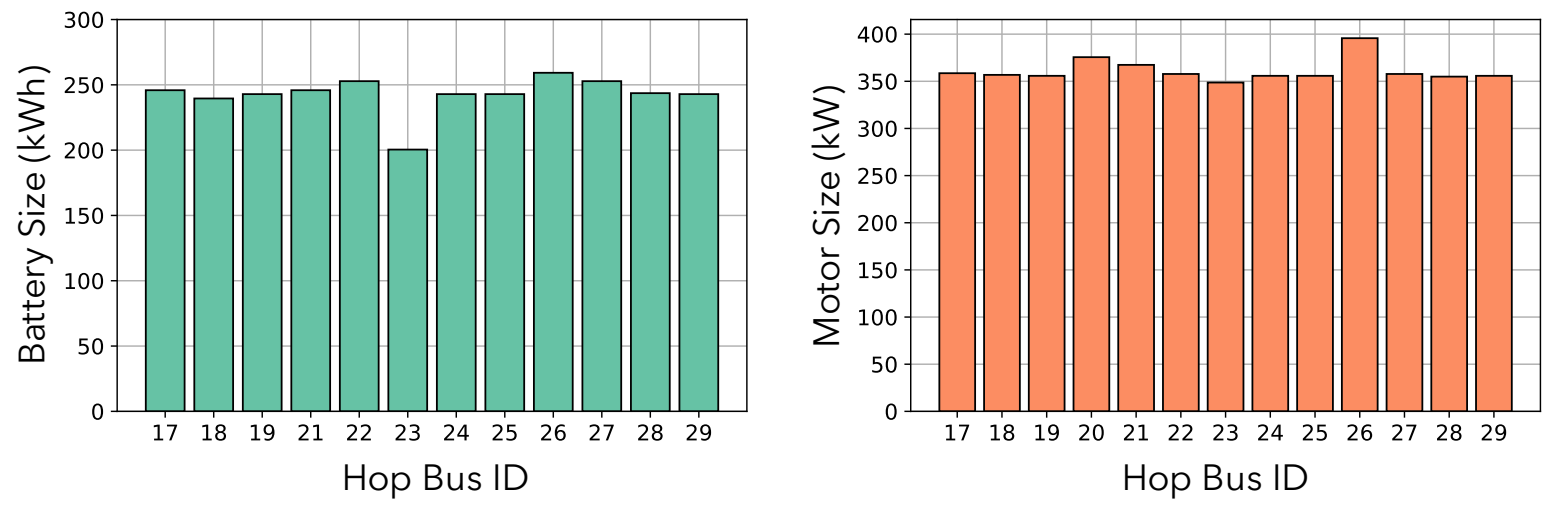

Figure 11. Bus battery and motor sizing results for the Via transit bus fleet 
In addition to sizing individual bus components, the Via data were used to infer requisite EVSE investment for fleet electrification. Outcomes from the EVSE sizing routine demonstrated that 6 charging plugs at a rate of $20 \mathrm{~kW}$ were sufficient for Via operations assuming the ability to share plugs between buses and no opportunity charging en-route. Note that selection of fewer plugs than buses would require cycling buses at the depot, potentially increasing labor costs. While the optimizer does confirm the logistics of sharing chargers across buses (no charger used by two buses simultaneously), labor costs are not explicitly considered in the optimization.

EVSE analysis assuming access to opportunity charging revealed that the battery size could be reduced significantly, from an average of $234 \mathrm{kWh}$ to an average of $75 \mathrm{kWh}$. The EVSE sizing routine under this scenario called for $630 \mathrm{~kW}$ charging ports across two en-route locations. The modest charge powers and battery sizes result from the mild operations of the Via transit fleet with respect to the total miles traveled as well as the plentiful time available at the depot overnight.

\section{Limitations, Conclusions, and Future Work}

Although the developed vehicle and EVSE sizing framework is intended to comprehensively support fleet electrification planning, there are limitations. First, the framework assumes a commitment to the current logistics and use patterns. The sizing routines are constrained by vehicle utilization as observed through data logging; optimal adoption and implementation may include logistics changes that are not captured within the framework. Next, the powertrain model is constrained by available input data and validation data; for example, while drivetrain physics are modeled, proprietary control strategies and battery management systems are not. This reality prevents differentiation between real-world bus models with similar component sizes but different controls. Finally, battery degradation is not explicitly modeled using the powertrain model, given lack of empirical degradation curves in response to driving, charging, and ambient effects.

Although limitations are acknowledged, the developed sizing routines are considered a significant improvement upon alternative planning methods. As mentioned in the introduction, real-world BEB performance has been found to be insufficient in many circumstances, whereby buses do not achieve advertised capabilities. The developed tool is capable of accounting for the real-world factors that plagued initial BEB pilots, including roadway topology, local climate, and duty cycle requirements. Furthermore, the model is capable of differentiating between buses servicing demanding routes and requiring larger batteries versus buses on milder routes that may require a smaller battery size. Finally, the commitment to meeting the needs of existing buses ensures conservative recommendations that will not require revisiting logistics.

Several additional areas of future inquiry have been identified. First, broader validation of the powertrain model is justified and will be easier as BEBs become ubiquitous, increasing the availability of validation data. Second, the need to physically instrument a logger is a barrier to planning assessments at scale. Research into upsampling of data retrieved from lower-frequency asset tracking devices using a repository of real-world cycles is a promising potential next step. Finally, additional work is proposed regarding application of the tool beyond transit buses to other depot-based transportation fleets. This would greatly enhance the scale of planning assessments. Although a new powertrain model would be required (such as for a parcel delivery vehicle), the majority of the developed framework would be capable of producing results for vehicle sizing and EVSE considerations. 


\section{References}

[1] J. Horrox and M. Casale. 2019. Electric Buses in America: Lessons from Cities Pioneering Clean Transportation. Denver, CO: U.S. PIRG Education Fund, Environment America Research and Policy Center. https://uspirg.org/sites/pirg/files/reports/ ElectricBusesInAmerica/US_Electric bus_scrn.pdf.

[2] Union of Concerned Scientists. 2019. Electric Utility Investment in Truck and Bus Charging: A Guide for Programs to Accelerate Electrification. Cambridge, MA: Union of Concerned Scientists. https://www.ucsusa.org/sites/default/files/attach/2019/04/ElectricUtility-Investment-Truck-Bus-Charging.pdf.

[3] California Air Resources Board. 2018. "California transitioning to all-electric public bus fleet by 2040.” Release Number 18-65, December 14, 2018, accessed March 16, 2021. https://ww2.arb.ca.gov/news/california-transitioning-all-electric-public-bus-fleet-2040.

[4] B. Heid, M. Kässer, T. Müller, and S. Pautmeier. 2018. "Fast Transit: Why Urban E-Buses Lead Electric-Vehicle Growth.” McKinsey Center for Future Mobility, September 2018, accessed March 16, 2021.

https://www.mckinsey.com/ /media/McKinsey/Industries/Automotive \%20and\%20Assembl y/Our $\% 20$ Insights/Fast $\% 20$ transit $\% 20$ Why $\% 20$ urban $\% 20 \mathrm{e} \% 20$ buses $\% 201$ ead $\% 20$ electric $\% 20$ vehicle $\% 20$ growth/Fast-transit-why-urban-e-buses-lead-electric-vehiclegrowth.pdf?shouldIndex=false.

[5] M. Wanek-Libman. 2020. "DART unveils Iowa's first battery electric bus." Mass Transit, Oct. 2, 2020, accessed March 16, 2021. https://www.masstransitmag.com/bus/vehicles/ hybrid-hydrogen-electric-vehicles/article/21156884/dart-unveils-iowas-first-batteryelectric-bus.

[6] B. Khatri. 2019. "Battery-Electric Bus Pilot Program.” SFMTA, Feb. 12, 2019, accessed March 16, 2021. https://www.sfmta.com/projects/battery-electric-bus-pilot-program.

[7] Metropolitan Transit System. 2018. "Zero Emissions Bus Pilot Program.” July 11, 2018, accessed March 16, 2021. https://www.sdmts.com/inside-mts-current-projects/zeroemissions-bus-pilot-program.

[8] L. Jin, O. Delgado, R. Gadpalli, and R. Minjares. 2020. "Strategies for deploying zeroemissions bus fleets: Development of real-world drive cycles to simulate zero-emission technologies along existing bus routes." International Council on Clean Transportation, Working Paper 2020-10. https://theicct.org/sites/default/files/publications/Drive-cycledevo-ZE\%20bus-082020.pdf.

[9] J. Dyer. 2019. “City, maker of electric ART buses settle suit.” Albuquerque Journal, May 31, 2019. https://www.abqjournal.com/1322358/city-settles-lawsuit-against-art-busmanufacturer.html.

[10] J. Aguilar. 2019. "RTD's electric 16th Street Mall buses cost nearly 60\% more to operate than diesel coaches." The Denver Post, May 14, 2019. https://www.denverpost.com/2019/05/14/rtd-mallride-shuttle-electric-diesel/.

[11] P. St. John. 2018. "Stalls, stops and breakdowns: Problems plague push for electric buses." Los Angeles Times, May 20, 2018. https://www.latimes.com/local/lanow/la-me-electricbuses-20180520-story.html. 
[12] E. Stoothoff. 2020. "Bus Electrification: Battery Electric Bus Performance." MBTA Fiscal and Management Control Board, September 14, 2020. https://cdn.mbta.com/ sites/default/files/2020-09/2020-09-14-fmcb-L-bus-electrification-accessible.pdf.

[13] L. Eudy, R. Prohaska, K. Kelly, and M. Post. 2016. Foothill Transit Battery Electric Bus Demonstration Results. Golden, CO: National Renewable Energy Laboratory. NREL/TP5400-65274. https://www.nrel.gov/docs/fy16osti/65274.pdf.

[14] L. Eudy and M. Jeffers. 2017. Foothill Transit Battery Electric Bus Demonstration Results: Second Report. Golden, CO: National Renewable Energy Laboratory. NREL/TP-540067698. https://www.nrel.gov/docs/fy17osti/67698.pdf.

[15] A. J. Kotz, E. Miller, A. Watson, and K. J. Kelly. 2020. "Transit Bus Electrification Evaluation from GPS Speed Traces.” Presented at the 2020 IEEE Transportation Electrification Conference Expo (ITEC), Chicago, IL, 23-26 June 2020. https://doi.org/10.1109/ITEC48692.2020.9161511.

[16] C. Hodge, M. Jeffers, J. Desai, E. Miller, and V. Shah. 2019. Surat Municipal Corporation Bus Electrification Assessment. Golden, CO: National Renewable Energy Laboratory. NREL/TP-5400-73600. https://www.nrel.gov/docs/fy19osti/73600.pdf.

[17] M. Gilleran, A. Kotz, L. Eudy, and K. Kelly. 2021. National Park Service Bus Electrification Study: 2020 Report. Golden, CO: National Renewable Energy Laboratory. NREL/TP-5400-78012. https:/www.nrel.gov/docs/fy21osti/78012.pdf.

[18] GCxN. 2021. "Shell GameChanger Powered by NREL.” Accessed March 16, 2021. https://gcxnrel.com/.

[19] J. Gonder, A. Brooker, E. Wood, and M. Moniot. 2018. Future Automotive Systems Technology Simulator (FASTSim) Validation Report. Golden, CO: National Renewable Energy Laboratory. NREL/TP-5400-71168. https://www.nrel.gov/docs/fy18osti/71168.pdf.

[20] National Renewable Energy Laboratory. 2021. "Fleet DNA: Commercial Fleet Vehicle Operating Data.” Accessed March 16, 2021. https://www.nrel.gov/transportation/fleettestfleet-dna.html.

[21] A. Kotz and C. Hodge. 2021. "Assessing Candidates for Electric Transit Buses." Submitted for publication.

[22] S. Wilcox and W. Marion. 2008. Users Manual for TMY3 Data Sets. Golden, CO: National Renewable Energy Laboratory. NREL/TP-581-43156. https://www.nrel.gov/docs/fy08osti/43156.pdf.

[23] Adafruit Industries. 2021. “Adafruit Feather M0 Adalogger.” Accessed March 16, 2021. https://www.adafruit.com/product/2796.

[24] J. A. Nelder and R. Mead. 1965. "A Simplex Method for Function Minimization.” The Computer Journal 7 (4): 308-313. doi: 10.1093/comjn1/7.4.308.

[25] Regional Transportation District. 2021. “HOP Route.” Accessed March 16, 2021. https://www.rtd-denver.com/hop. 